\title{
Diet, infection, and acute appendicitis in Britain and Ireland
}

\author{
JULIE MORRIS, DJP BARKER, AND M NELSON \\ From the MRC Environmental Epidemiology Unit, University of Southampton, Southampton General Hospital, \\ Southampton SO9 $4 X Y$
}

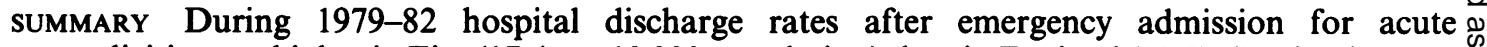
appendicitis were higher in Eire (17.4 per 10000 population) than in England (10.3), Scotland (11.1), $\vec{\circ}$ or Wales (12.3). Comparison of food consumption between the four countries, and between the health board areas of Eire and regions of Scotland, shows that appendicitis rates are highest in $\vec{\omega}$ communities that consume more potatoes, sugar, and cereals, and less non-potato vegetables and $\frac{\mathscr{S}}{\widehat{D}}$ fruit. The rates are also related to mortality from enteric and respiratory infections, to general $\stackrel{\odot}{\circ}$ practice consultations for infective disease, and to postneonatal mortality. This is evidence in favour of the hygiene hypothesis for the aetiology of appendicitis.

The steep increase in incidence of appendicitis in Britain at the turn of the century coincided with changes in the national diet. This, together with the observation that the disease was common only in industrialised countries, led to hypotheses that it had dietary causes, with particular interest in fibre and sugar. ${ }^{2}$ None of these hypotheses, however, can explain the continuing decline in the disease since the 1930s. ${ }^{3}$ Nor have case-control studies yielded consistent evidence implicating any food or nutrient other than an association with low fluid intake. ${ }^{4}$ Interest in the hypothesis that appendicitis is primarily an infective disorder has therefore revived. ${ }^{56}$ In particular, it has been suggested that the rise in appendicitis was a consequence of the Public Health Acts at the end of the last century. The resulting improvements in hygiene greatly reduced young children's exposure to enteric organisms and, it is argued, could thereby have altered their responses to infection in later years in such a way that acute appendicitis was triggered. ${ }^{3}$

A recent study of appendicitis rates in 59 areas of England and Wales showed a positive correlation with consumption of potatoes and a negative correlation with non-potato vegetables, in particular green vegetables and tomatoes. ${ }^{7}$ In addition, there was a positive correlation with sugar and a negative correlation with fruit, although these were not consistent. Correlations with cereal foods and cereal fibre were small and not significant.

In order to examine further the roles of diet and infection in the aetiology of appendicitis we have extended these observations to include Scotland and Eire (the Republic of Ireland).

\section{Methods}

\section{APPENDICITIS DATA}

The Medico-Social Research Board in Dublin provided Hospital In-patient Enquiry (HIPE) data on discharges following appendicitis in Eire during 197982. For each of the eight health board areas in Eire discharge rates were calculated from the numbers of $\frac{\mathscr{Q}}{D}$ patients resident in the area who had (a) been $\cong$ discharged from hospital with the diagnosis of $\overrightarrow{\overrightarrow{0}}$ appendicitis (International Classification of Disease (ICD), eighth revision, codes 540,541 ), (b) been admitted as emergencies, and (c) undergone appendicectomy (Office of Population Censuses and $\bar{\varnothing}$ Surveys numbers 441,444 ). Use of these criteria was $\stackrel{\odot}{-}$ intended to exclude patients with non-acute appendicitis.

The coverage of the HIPE scheme in Eire varies $\delta$ from year to year and between health boards. The $₹$ average coverage in each board throughout 1979-82을 varied from 57 to $91 \%$ of all admissions. Discharge $>$ rates for appendicitis were adjusted using these coverage figures. The coverage of paediatric and $\vec{N}$ emergency admissions is, however, higher than for all $\mathrm{N}$ admissions and approaches $100 \%$ in some areas. N Therefore the unadjusted rates are likely to be closer to $\underset{\mathrm{W}}{ }$ the true rates.

Published HIPE data ${ }^{8}$ and Scottish Hospital Inpatient Statistics ${ }^{9}$ were used to calculate discharge 
rates for England, Wales, and Scotland. The Scottish data include non-acute appendicitis (ICD, eighth revision, codes 542-3): rates were made comparable to those from the other three countries by applying a correction factor of 0.86 , which HIPE data for England and Wales show to be the proportion of emergency admissions for acute appendicitis out of all admissions for appendicitis. The rates for each country were directly standardised for age and sex using the population of England in 1980 as the standard. Rates for the hospital board regions of Scotland during 1979-82 were not standardised because age-sex specific rates were not published.

For the examination of time trends in Scotland the Scottish Health Service Common Services Agency provided data on discharges following acute appendicitis, as defined for Eire, during 1961-74.

\section{DIET ARY DATA}

The 1980 Household Budget Survey in Eire recorded expenditure on food during a fortnight in a national sample of 7185 households. ${ }^{10}$ Average weekly expenditure per household on 118 food groups was calculated for each of the eight planning regions. Using published information on food prices, we estimated daily food consumption per person. ${ }^{11}$ The boundaries of four planning regions correspond exactly with those of four health board areas. The remaining planning regions and health boards correspond approximately. We could therefore estimate average daily food consumption per person by health board.

Food consumption figures for England, Wales, and Scotland during 1979-82 were obtained from data from the National Food Survey ${ }^{12}$ (NFS), which each year records food purchases within a sample of parliamentary constituencies. Foods listed by the NFS were grouped according to the definitions used in the Household Budget Survey.

\section{INFECTIONS}

As one indicator of the incidence of infection we used published mortality from infective and parasitic disease (ICD, sixth and seventh revisions, B1-17, eighth revision B1-18). ${ }^{13-15}$ To make data before 1968 comparable to those for later years, we added to deaths coded under the sixth and seventh revisions those coded under B36 (enteritis and related diseases) and ICD 764 (neonatal diarrhoea). As a second indicator of infection we used postneonatal mortality rates. ${ }^{1214}$

A third indicator of infection came from the 1970 71 National Morbidity Survey, ${ }^{16}$ which recorded consultations in 53 practices throughout England and Wales during one year. Consultations for infective disesase (ICD, eighth revision B1-18) are published as patients consulting rates per thousand population per standard region. There are no corresponding data for Scotland and Eire.

\section{Results}

Table 1 shows average annual discharge rates following acute appendicitis in the four countries. The rate for Eire is 17.4 per 10000 or 21.7 when adjusted to allow for incomplete coverage by HIPE. The true value will be between these figures and is higher than the rates for the other three countries: in descending order, Wales (12.3), Scotland (11.1), and England (10.3). Among the eight health boards of Eire rates tend to be highest in those in the north and west.

Table 2 shows rates for the five regional hospital boards of Scotland in 1961-74. While, as elsewhere in Britain, the rates progressively declined during this period, from 24.4 per 10000 in all regions combined in $1961-63$ to $17 \cdot 3$ in 1972-74, those for the northern region consistently remained the highest. By 1979-82 values (unstandardised) had fallen to 14.4 in the north, 10.1 in the north-east, 12.4 in the east, 10.2 in the south-east, and 11.5 in the west.

Average daily food consumption figures for the four countries are shown in table 3 . Potato consumption had a positive association with appendicitis, being

Table 1 Average annual hospital discharge rates for acute appendicitis per 10000 population, 1979-82

\begin{tabular}{lll}
\hline Country & Rate & Adjusted rate* \\
\hline England & 10.3 & - \\
Scotland & $11 \cdot 1$ & - \\
Wales & 12.3 & - \\
Eire & $17 \cdot 4$ & $21 \cdot 7$ \\
North-western & 22.0 & $24 \cdot 2$ \\
North-eastern & 21.8 & 25.0 \\
Western & 21.2 & $24 \cdot 3$ \\
South-eastern & 18.9 & 28.3 \\
Mid-western & 16.7 & 21.6 \\
Eastern & $16 \cdot 1$ & $19 \cdot 0$ \\
Midland & 14.3 & $24 \cdot 1$ \\
Southern & 13.6 & 18.4 \\
\hline Rates adjusted for incomplete coverage of HIPE scheme using coverage figures
\end{tabular}

for all admissions.

Table 2 Average annual hospital discharge rates for acute appendicitis standardised for age and sex per 10000 population in the regional hospital boards of Scotland, 1961-74

\begin{tabular}{lllll}
\hline Region & $1961-63$ & $1964-67$ & $1968-71$ & $1972-74$ \\
\hline North & $37 \cdot 1$ & 36.8 & 31.2 & 24.8 \\
North-east & 24.4 & 22.6 & 17.9 & 14.7 \\
East & 24.6 & 24.7 & 20.9 & 19.5 \\
South-east & 26.8 & 25.8 & 21.4 & 17.8 \\
West & 22.7 & 22.6 & 18.8 & 16.6 \\
All regions & 24.4 & 24.0 & 20.0 & 17.3 \\
\hline
\end{tabular}


Table 3 Food consumption (g/person/day) in Eire (1980) and England, Wales, and Scotland (1979-82)

\begin{tabular}{lcccc}
\hline Food group & Eire & Wales & Scotland & England \\
\hline All vegetables & 368 & 379 & 314 & 343 \\
Vegetables other & & & & \\
than potatoes & 119 & 167 & 130 & 173 \\
Potatoes & 249 & 212 & 184 & 170 \\
Green vegetables & 46 & 60 & 34 & 60 \\
Tomatoes & 10 & 15 & 12 & 16 \\
Fruit & 77 & 89 & 77 & 93 \\
Sugar & 65 & 50 & 44 & 44 \\
All cereal foods & 305 & 234 & 239 & 223 \\
\hline
\end{tabular}

highest in Eire (249g per person per day) and lowest in England $(170 \mathrm{~g})$. Consumption of sugar and cereal foods also showed a positive association with highest levels in Eire (sugar 65g per person per day, cereals $305 \mathrm{~g}$ ). In contrast, green vegetable, tomato, and fruit consumptions were negatively associated with appendicitis. Levels for green vegetables were lowest in Eire (46g per person per day) and in Scotland $(34 \mathrm{~g})$ and highest in England and Wales $(60 \mathrm{~g})$. Levels for tomatoes were lowest in Eire $(10 \mathrm{~g})$ and highest in England (16g). Consumption of fruit was lowest in Eire (77g) and Scotland (77g) and highest in England (93g).

We calculated the Spearman rank correlation coefficient between average daily food consumption in each of the health boards of Eire and appendicitis rates, unadjusted (table 4). In keeping with the trends between the countries, there are positive correlations with potatoes $(r=0.31)$, sugar $(r=0.24)$, and cereal foods $(r=0.52)$ and negative correlations with green vegetables $(r=-0 \cdot 38)$, tomatoes $(r=-0 \cdot 29)$, and fruit $(r=0.64)$. Substitution of adjusted appendicitis rates reduces the coefficients for cereal foods and green vegetables and makes the correlation with tomatoes positive. None of the correlations with unadjusted or adjusted rates is statistically significant.

Table 5 shows food consumption within the regional hospital boards of Scotland. We did not calculate correlation coefficients because there are

Table 4 Correlation between food consumption and hospital discharge rates for acute appendicitis in eight health board areas in Eire

\begin{tabular}{llcl}
\hline Food group & $\begin{array}{l}\text { Consumption } \\
(\mathrm{g} / \text { person/day })\end{array}$ & Range & $\begin{array}{l}\text { Correlation } \\
\text { coefficient }\end{array}$ \\
\hline All vegetables & 368 & $333-409$ & -0.05 \\
Vegetables other & 119 & $96-125$ & -0.43 \\
than potatoes & 119 & $211-299$ & 0.31 \\
Potatoes & $38-54$ & -0.38 \\
Green vegetables & 46 & $8-12$ & -0.29 \\
Tomatoes & 10 & $64-87$ & -0.64 \\
Fruit & 77 & $53-77$ & 0.24 \\
Sugar & 65 & $272-356$ & 0.52 \\
All cereal foods & 305 & & \\
\hline
\end{tabular}

Table 5 Food consumption (g/person/day) in the regional hospital boards of Scotland (1979-82)

\begin{tabular}{lrrrrr}
\hline Food group & North & \multicolumn{2}{l}{ North-east } & East & \multicolumn{2}{c}{ South-east } & West \\
\hline All vegetables & 319 & 301 & 318 & 301 & 317 \\
Vegetables other & & & & & \\
than potatoes & 118 & 110 & 136 & 134 & 125 \\
Potatoes & 201 & 191 & 182 & 168 & 192 \\
Green vegetables & 28 & 30 & 38 & 37 & 33 \\
Tomatoes, fresh & 13 & 11 & 14 & 16 & 11 \\
Fruit & 87 & 62 & 88 & 87 & 67 \\
Sugar & 55 & 54 & 44 & 39 & 44 \\
All cereal foods & 236 & 194 & 236 & 229 & 254 \\
\hline
\end{tabular}

only five regions. Other than for fruit and tomatoes the trends are consistent with those between the countries, and within Eire. The northern region, with the highest appendicitis rates, has the highest consumption of potatoes and sugar and the lowest consumption of green vegetables.

The relation between appendicitis, 1979-82, and consumption of non-potato vegetables in the health board areas of Eire and the regions of Scotland, England, and Wales is displayed in figure 1. Rates for Eire are unadjusted. The product-moment correlation coefficient is $-0.72, p<0.001$.

The trends in all-ages mortality from infective disease in the four countries during 1958-82 are showm in table 6. Although they declined steeply, those in Eire remained consistently the highest, while those iu. Wales and Scotland were higher than those i $\infty$ England. Exclusion of tuberculosis, the major cause of death in this group, reduces the rates by around half. The differences between the countries, however, are preserved except that rates in Wales move closer to those in England.

By 1979-82, the period for which appendicitis data in Eire are available, infective disease mortality rates

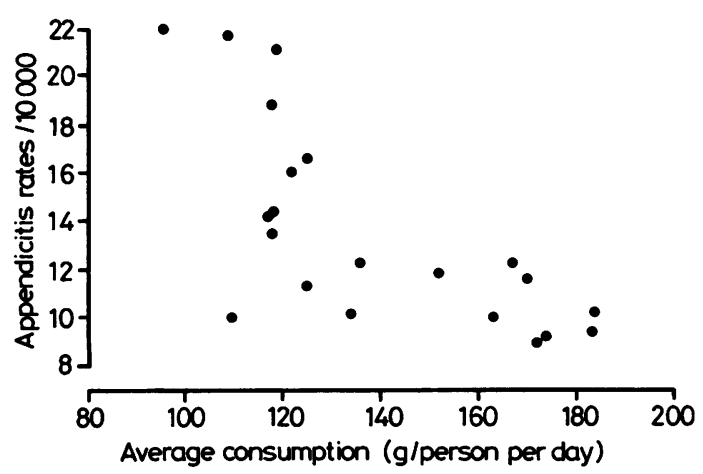

Fig 1 Consumption of vegetables other than potatoes and discharge rates for acute appendicitis, 1979-82, in Eire, Wales, the regions of England, and the regional hospital boards of Scotland. 
Table 6 Average annual death rates from infective disease per 100000 population in Eire, England, Scotland, and Wales, $1958-82$

\begin{tabular}{llllll}
\hline Country & $1958-62$ & $1963-67$ & $1968-72$ & $1973-77$ & $1978-82$ \\
\hline Eire & 28.8 & 22.7 & 14.2 & 10.5 & 8.8 \\
Wales & 19.9 & 15.6 & 8.8 & 6.5 & 5.3 \\
Scotland & 19.6 & 15.2 & 9.9 & 7.8 & 5.6 \\
England & 16.1 & 12.9 & 7.0 & 5.5 & 4.2 \\
\hline
\end{tabular}

had become low and the differences between countries small. Figure 2 relates the appendicitis rates in Eire, Wales, and the regions of England and Scotland with mortality from infective disease 20 years earlier, 1959-62. There is a high correlation, with a product moment correlation coefficient of $0.81, \mathrm{p}<0.001$. After removal of deaths from tuberculosis the coefficient is slightly reduced to $\mathbf{0 . 8 0}$. Although Eire exerts a strong influence, the correlation persists, $r=0.59, p=0.02$, after its exclusion. The correlation between appendicitis rates, 1979-82, in Eire, Wales, the regions of England, and Scotland, and postneonatal mortality, 1959-62, is also significant, $\mathrm{r}=0.57, \mathrm{p}=0.02$.

Figure 3 shows appendicitis rates, 1969-72, and patients consulting rates for infective disease, 1970-71, in Wales and the regions of England. They are highly correlated, $\mathrm{r}=0.84, \mathrm{p}=0.005$.

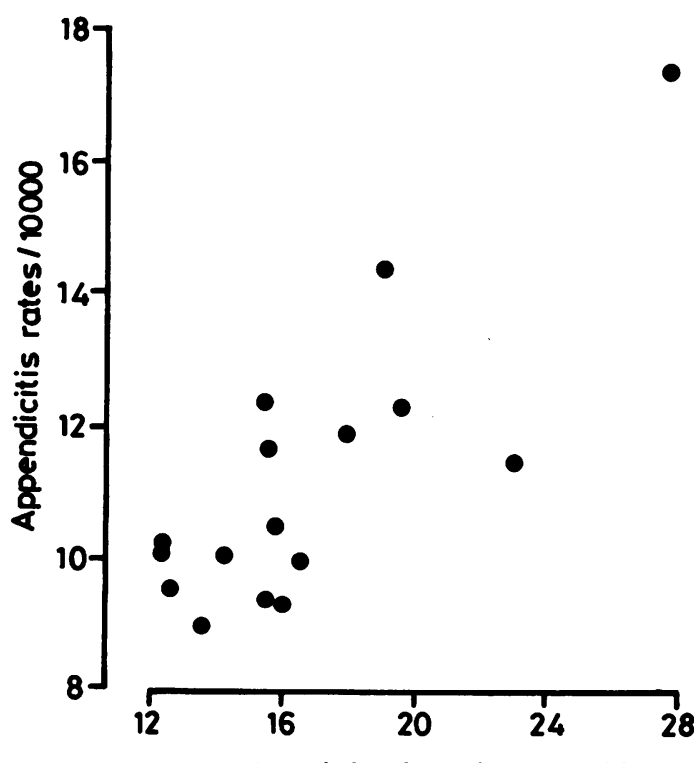

Deaths from infective disease $/ 100000$

Fig 2 Mortality from infective disease, 1959-62, and discharge rates for acute appendicitis, 1979-82, in Eire, Wales, the regions of England, and the regional hospital boards of Scotland.

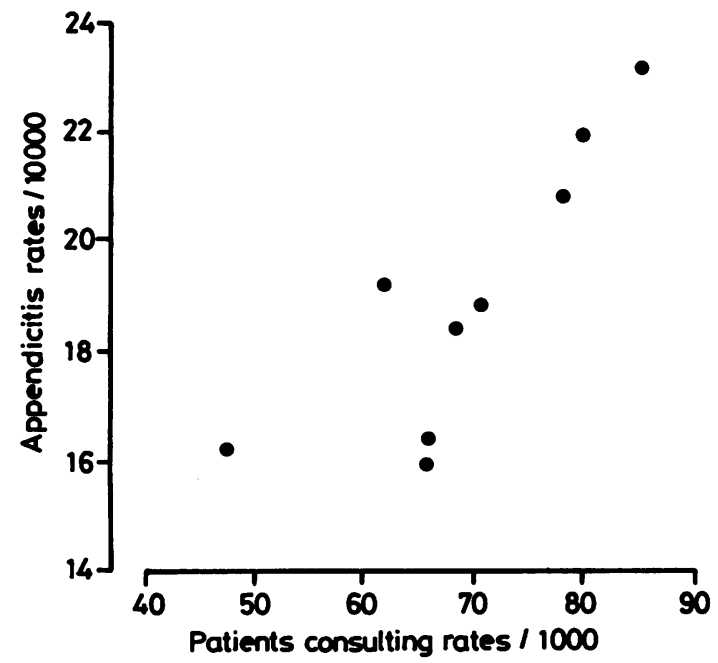

Fig 3 Patients consulting rates for infective disease, 1970-71, and discharge rates for appendicitis, 1969-72 in Wales and the regions of England

\section{Discussion}

Hospital discharge rates following emergency admission for acute appendicitis are higher in Eire than in England, Scotland, or Wales (table 1). Although the coverage of the HIPE system in Eire is incomplete, and there are no specific data for the coverage of acute appendicitis, the lowest estimate for Eire, 17.4 per 10000 population per year, is considerably above the rates in the other three countries. Within Eire rates tend to be highest in the north and west where they are around 20 per 10000 . Values comparable to this, during the same period, have been recorded elsewhere in the British Isles only in Anglesey (20.6 per 10000$)^{7}$ and the Isle of Man (25.1) (S Parkes, personal communication). Similarly high rates were seen in northern Scotland during the early 1970s but these have since declined (table 2).

An objection to these data is that a varying proportion of removed appendices are histologically normal, but for various reasons the diagnosis of acute appendicitis may still appear on hospital records. Hospital discharge rates therefore overestimate the incidence of acute appendicitis, and variations between areas could reflect different recording practices and surgical policies as well as variations in incidence. In a recent detailed survey of a sample of hospital discharges in Eire, the percentage of removed appendices showing pathological changes of acute appendicitis was around $70 \%$ (West, unpublished data). Similar figures have been recorded in a survey in nine British towns, ${ }^{17}$ in Anglesey, and in the Isle of 
Man. We therefore conclude that there are variations in the incidence of appendicitis between and within Eire, England, Scotland, and Wales.

Our comparison of food consumption between the four countries (table 3) was based on data from two different sources, the Household Budget Survey in Eire and the National Food Survey in Britain. The former is subject to error since food consumption was estimated from regional household expenditure on food and food prices in Dublin. The large differences between Eire and England, however, are unlikely to be due solely to inaccuracies. The comparison between the countries is consistent with findings in 59 areas of England and Wales that appendicitis is associated with high consumption of potatoes and sugar and low consumption of non-potato vegetables, particularly green vegetables and tomatoes and fruit. ${ }^{7}$ Whereas within England and Wales there was no association with cereal foods, comparison between the countries, particularly the high cereal food consumption in Eire, suggests a positive association. Comparisons between the health boards of Eire and the hospital board regions of Scotland are broadly consistent with those between the countries. They are not statistically significant and are subject to error, for example because of lack of regional data on food prices in Eire. Such errors, however, might be expected to conceal associations rather than create spurious ones.

We conclude that in Britain and Eire appendicitis has a higher incidence in communities with high consumption of potatoes, sugar, and cereals, and a lower incidence in communities with high consumption of non-potato vegetables, in particular green vegetables and tomatoes, and of fruit. The most consistent of these dietary associations of appendicitis are those with potatoes, all non-potato vegetables (fig 1) and sugar. On the basis of the findings in England and Wales, we have suggested that the association with potatoes reflects the inverse relation between their consumption and that of other vegetables, which protect against appendicitis. We can offer no explanation of the correlation with sugar. The high consumption of cereal foods in Eire is further evidence against the hypothesis that cereal fibre protects against appendicitis.

There is general agreement that the ultimate event in appendicitis is invasion of the distal appendicular wall by organisms from within the lumen. Debate centres on the preceding events. A recent hypothesis suggests that the dramatic rise in appendicitis at the beginning of this century was the result of the environmental changes brought about by Public Health reforms in the late $1800 \mathrm{~s}^{3}$ The consequent improvements in hygiene greatly reduced exposure of young children to enteric organisms, demonstrated by the fall in childhood mortality from diarrhoeal disease. It is postulated that this altered the response to later infections in such a way that they triggered acute appendicitis. These triggering infections could be enteric or respiratory organisms. The initiating event may be lymphoid hyperplasia in the appendicular wall and consequent obstruction of the proximal lumen. Alternatively, it may be invasion of the appendicular epithelium by enteric organisms with or without preceding obstruction. No evidence of obstruction is found in $50 \%$ of cases of appendicitis. ${ }^{18}$

The 'hygiene' hypothesis suggests that whereas the rise in incidence of appendicitis in Britain was due to an increase in the propensity to develop the disease following a triggering infection, the decline is due to reduced encounters with triggering infections Consequently, the geographical variations in the disease in England, Scotland, and Wales where rates are known to be declining should reflect variations in the incidence of infection. The data in figs 2 and 3 and the correlation with postneonatal mortality are consistent with this. The high infective disease and postneonatal mortality in Eire are also consistent, although data to confirm a current decline in appendicitis are lacking.

Mortality from infective disease is now so low that it can no longer serve as an indicator of geographicak differences in incidence of infection in Britain and Eire (table 6). We therefore used mortality rates from 20 years ago. The correlation with current appendicitio. rates is strikingly high and is little influenced by exclusion of tuberculosis (fig 2).

In England and Wales, data from the National Morbidity Survey of consultations in general practice allow comparison of morbidity from infection and appendicitis rates during the same period (fig. 3 ). The high correlation supports the argument that acute appendicitis is triggered by infection. Both the mortality and morbidity data are crude indicators of a range of different infections but their similar regional pattern in England and Wales supports their validity. We have found no other indicators, and the data provide only limited support for the infective aetiology of appendicitis.

The finding that in Britain and Eire communities with high appendicitis rates are characterised by particular patterns of both food consumption and infective disease can be interpreted in a number of ways. The geographical relation between diet and appendicitis may not be causal but may reflect an association between diet and socioeconomic influences. Consumption of green vegetables and fruit is historically and currently highest in the upper income groups in Britain. ${ }^{12} 19$ Consumption of potatoes, sugar, and cereals is highest in the lower income groups. Hence geographical differences in intake of these foods may reflect differences in other 
economic variables. The quality of housing, in relation to crowding, density, and the availability of amenities such as hot and cold water, is a known determinant of infection. We are investigating further the possible relation between appendicitis and housing.

We thank Dr Emer Shelley and Dr Rosemary Hamill for their help in analysis of data provided by the Medico-Social Research Board in Dublin. The Scottish Health Services Common Services Agency kindly supplied the data for Scotland.

\section{References}

${ }^{1}$ Rendle Short A. The causation of appendicitis. Br J Surg 1920; 8: 171-88.

${ }^{2}$ Burkitt DP. The aetiology of appendicitis. Br J Surg 1971; 58: 695-9.

${ }^{3}$ Barker DJP. Acute appendicitis and dietary fibre: an alternative hypothesis. $\mathrm{Br}$ Med $J$ 1985; 290: 1125-7.

${ }^{4}$ Nelson M, Morris J, Barker DJP, Simmonds S. A casecontrol study of acute appendicitis and diet in children. J Epidemiol Comm Health 1986; 40: 316-8.

5 Aschoff L (translated by Pether GC). Appendicitis, its aetiology and pathology. London: Constable, 1932.

${ }^{6}$ Medical Research Council Environmental Epidemiology Unit. Scientific Report No. 7. The aetiology of acute appendicitis. Southampton, 1986.
${ }^{7}$ Barker DJP, Morris J, Nelson M. Vegetable consumption and acute appendicitis in 59 areas in England and Wales. Br Med J 1986; 292: 927-30.

${ }^{8}$ Report on the hospital in-patient enquiry. London: HMSO, 1969 and following years.

${ }^{9}$ Scottish hospital in-patient statistics. Information services division of the Common Services Agency, 1979 and following years.

${ }^{10}$ Household budget survey, Vol 2. Dublin: Central Statistics Office, 1980.

${ }^{11}$ Consumer prices in the EC. Statistical Office of the European Communities, 1980.

${ }^{12}$ Ministry of Agriculture, Fisheries and Food. Household food consumption and expenditure 1979-1982. London: HMSO.

${ }^{13}$ The Registrar General's statistical review of England and Wales: Part 1 Tables, Medical. London: HMSO, 1958 and following years.

14 Annual report of the Registrar General for Scotland. Edinburgh: HMSO, 1958 and following years.

${ }^{15}$ Statistical abstracts of Ireland. Dublin: Central Statistics Office, 1958 and following years.

${ }^{16}$ Morbidity statistics from general practice: second national study 1970-71. London: HMSO, 1974.

${ }^{17}$ Barker DJP, Liggins A. Acute appendicitis in nine British towns. Br Med J 1981; 283: 1083-5.

${ }^{18}$ Read N. Pathophysiological mechanisms in the appendix. In: The aetiology of acute appendicitis. Medical Research Council Environmental Epidemiology Unit, Conference Report No. 7. Southampton, England, 1986.

19 Orr JB, Food, health and income. Second edition. London, 1937. 